\title{
Papers
}

\section{p53 alterations in oesophageal cancer: association with clinicopathological features, risk factors, and survival}

\author{
A G Casson, M Tammemagi, S Eskandarian, M Redston, J McLaughlin, H Ozcelik
}

\begin{abstract}
Aim-To characterise the spectrum of p53 alterations (gene mutations and protein accumulation) in a consecutive series of surgically resected oesophageal cancers, and to evaluate associations with clinicopathological findings (age, sex, tumour histology, grade, and stage), potential risk factors (alcohol, tobacco, hot beverage consumption, history of gastrooesophageal reflux disease and antacid use), and survival.
\end{abstract}

Methods-The case series comprised 61 sequentially accrued patients with primary oesophageal carcinomas. Genomic DNA was extracted from banked (frozen) tumours and matched normal mucosal tissue; p53 mutations (exons 4-10) were studied by means of polymerase chain reaction (PCR)/single strand conformation polymorphism (SSCP) analysis and DNA sequencing. Immunohistochemistry (DO7, CM1) was used to assess cell nuclear p53 protein accumulation. Risk factor data, overall and disease free survival were measured prospectively, and analysis was carried out at the univariate level using Kaplan-Meier survival curves with log rank tests, and in multivariate analysis using Cox's proportional hazards models (parsimonious and fully adjusted). Results-p53 mutations were found in 59\% (36 of 61) and p53 protein accumulation was detected in 39\% (24 of 61) of oesophageal cancers. Eighty eight per cent ( 23 of 26) of poorly differentiated tumours had p53 alterations compared with $57 \%$ (20 of 35) of moderate/well differentiated tumours (odds ratio $(\mathrm{OR})=5.575$; $p=0.013) \cdot p 53$ mutations increased significantly with increasing consumption of hot beverages (measured by the average temperature of beverage, number consumed daily, and an index made by multiplying the two variables together) using both univariate $(O R=18.6 ; p=0.0025)$ and multivariate $(\mathrm{OR}=24.5 ; \mathrm{p}=0.0025)$ analysis. $\mathrm{p} 53$ alterations were associated with reduced disease free and overall survival $(p=0.051$, $\log$ rank), with a univariate (unadjusted) hazard ratio (HR) of 2.241 (95\% confidence limits $(C L)=0.973,5.159 ; p=0.058)$ for overall survival. By multivariate analysis adjusted for other relevant variables, the HR for tumours with p53 alterations was estimated at $2.913(95 \% \mathrm{CL}=1.069,7.936$; $p=0.036$ ) for overall survival

Conclusions-This study reports novel p53 mutations (exon 10), and an association between increasing consumption of hot beverages as a risk factor for p53 mediated oesophageal cancer. p53 is a potentially useful prognostic marker in this disease. (f Clin Pathol: Mol Pathol 1998;51:71-79)

Keywords: oesophageal cancer; p53; prognosis

Despite recent advances in multimodality therapy, the prognosis for invasive oesophageal cancer is poor, with five year survival generally below $10 \% .{ }^{12}$ While improvements in survival may be anticipated with early detection and the rational use of adjuvant therapies, it is most likely that significant progress in the treatment of this disease will only occur with an improved understanding of its tumour biology and careful evaluation of clinically relevant molecular markers.

The p53 tumour suppressor gene appears to have a central role in human neoplasia, ${ }^{34}$ and mutations were first reported in oesophageal squamous cell carcinomas by Hollstein et al in $1990 .^{5}$ Using strict criteria to define adenocarcinomas of oesophageal origin, we reported p53 mutations in primary oesophageal adenocarcinomas and associated Barrett's epithelium. ${ }^{6}$ These original observations have been confirmed in oesophageal adenocarcinomas by other investigators, documenting additional p53 mutations, ${ }^{7-16}$ altered expression of p53 mRNA, ${ }^{17}{ }^{18}$ p53 protein accumulation, ${ }^{19-24}$ and loss of heterozygosity of chromosome $17 \mathrm{p.}^{25-27}$

Despite this increasing amount of information, the precise role of p53 in oesophageal tumorigenesis and the potential clinical significance of these observations remains unclear. Studies evaluating the prognostic use of p53 protein, detected immunohistochemically primarily in oesophageal squamous cell
Professor Casson.

Accepted for publication 13 January 1998 
Table 1 p53 alterations (mutations and protein accumulation) in primary oesophageal adenocarcinomas and squamous cell carcinomas

\begin{tabular}{|c|c|c|c|c|c|c|}
\hline UICC $\operatorname{stage}^{50}$ & $\operatorname{SSCP}(+/-)$ & Exon & Codon & Base & Type & IHC score \\
\hline \multicolumn{7}{|c|}{ Adenocarcinomas } \\
\hline III & + & 4 & 91 & $+\mathrm{G}$ & FS & 0 \\
\hline IV & + & 5 & 154 & $+\mathrm{C}$ & FS & 0 \\
\hline III & + & 5 & 158 & CGC-CAC & Arg-His & 8 \\
\hline IIB & + & 5 & 158 & CGC-CAC & Arg-His & 0 \\
\hline IV & + & 5 & 163 & TAC-TGC & Tyr-Cys & 7 \\
\hline IV & + & 5 & 174 & $-\mathrm{G}$ & FS & 0 \\
\hline III & + & 5 & 175 & CGC-CAC & Arg-His & 8 \\
\hline IIA & + & 5 & 175 & CGC-CAC & Arg-His & 8 \\
\hline IIA & + & 5 & 175 & CGC-CAC & Arg-His & 0 \\
\hline IIA & + & 5 & 175 & CGC-CAC & Arg-His & 0 \\
\hline III & + & 5 & 179 & CAT-TAT & His-Tyr & 0 \\
\hline III & + & 6 & 196 & CGA-TGA & Arg-Stop & 0 \\
\hline IV & + & 6 & 196 & CGA-TGA & Arg-Stop & 0 \\
\hline IIA & + & 7 & 234 & TAC-AAC & Tyr-Asn & 6 \\
\hline III & + & 7 & 234 & TAC-TGC & Tyr-Cys & 5 \\
\hline I & + & 7 & 236 & $+\mathrm{TA}$ & FS & 0 \\
\hline I & + & 7 & 245 & GGC-AGC & Gly-Ser & 6 \\
\hline III & + & 7 & 248 & CGG-TGG & Arg-Trp & 8 \\
\hline III & + & 8 & 271 & GAG-TAG & Glu-Stop & 0 \\
\hline III & + & 8 & 273 & CGT-CAT & Arg-His & 8 \\
\hline IIA & + & 8 & 273 & CGT-TGT & Arg-Cys & 4 \\
\hline III & + & 8 & 282 & CGG-TGG & Arg-Trp & 0 \\
\hline IIA & + & 8 & 306 & CGA-TGA & Arg-Stop & 6 \\
\hline III & + & 8 & 306 & CGA-TGA & Arg-Stop & 4 \\
\hline IV & + & 9 & 311 & AAC-CAC & Asp-His & 8 \\
\hline III & + & 9 & 316 & $+\mathrm{C}$ & $\mathrm{FS}$ & 0 \\
\hline IIA & + & 10 & 334 & $-G$ & FS & 6 \\
\hline IV & + & 10 & 342 & CGA-TGA & Arg-Stop & 0 \\
\hline III & - & & & & & 8 \\
\hline III & - & & & & & 7 \\
\hline IIA & - & & & & & 5 \\
\hline III & - & & & & & 4 \\
\hline III & - & & & & & 4 \\
\hline \multicolumn{7}{|c|}{ Squamous cell carcinomas } \\
\hline IV & + & 4 & 106 & -CTA & $-\mathrm{Tyr}$ & 7 \\
\hline III & + & 5 & $158-160$ & -CGCGCCA & FS & 4 \\
\hline IIA & + & 5 & 173 & GTG-TTG & Val-Leu & 7 \\
\hline IIB & - & 6 & 224 & GAG-GTG & Splice site & 0 \\
\hline II & + & 8 & 266 & GGA-TGA & Gln-Stop & 0 \\
\hline IIA & + & 8 & 293 & $+\mathrm{A}$ & FS & 0 \\
\hline IIA & + & 9 & 317 & CAG-TAG & Gln-Stop & 0 \\
\hline III & + & 10 & 349 & GAA-TAA & Gln-Stop & 7 \\
\hline III & - & & & & & 4 \\
\hline
\end{tabular}

Histology: Sq, squamous cell carcinoma; Ad, adenocarcinoma, of primary oesophageal origin according to strict criteria. ${ }^{6}$

SSCP, single strand conformation polymorphism analysis. + , electrophoretic mobility shift indicative of a point mutation; -, no shift.

Type: Gln, glutamine; Arg, arginine; His, histidine; Tyr, tyrosine; Trp, tryptophan; Ser, serine; Cys, cysteine; Gly, glycine; Val, valine; Leu, leucine; Glu, glutamic acid; Asn, asparagine; Stop, stop codon; FS, frameshift.

IHC score: immunohistochemistry score ${ }^{40}$ a composite of the proportion score $[0-5]$ and intensity score [0-3]. Immunonegative sections score 0 . Immunopositive sections score $2-8$.

carcinomas and in a few adenocarcinomas, have reported conflicting results. ${ }^{28-36}$ Several factors might account for these discordant findings, including the use of different anti-p53 antibodies, variation in interpretation of immunohistochemical sections, patient demographics, variable use of induction therapy, differing operative procedures, lack of accurate tumour staging, and the use of inappropiate study design and analytical methods. To date, only one study has evaluated the prognostic value of p53 mutations (exons 5-8) in oesophageal carcinoma, ${ }^{37}$ using only single strand conformation polymorphism (SSCP) analysis.

This prospective study was initiated in 1991 with the following objectives: to characterise the spectrum of p53 alterations (mutations and protein) in a consecutive series of surgically resected oesophageal cancers, and to evaluate associations with clinicopathological findings (patient age, sex, tumour histology, grade, and stage), potential risk factors (alcohol, tobacco and hot beverage consumption, history of gastro-oesophageal reflux disease and antacid use), and survival. The following results help resolve many earlier inconsistencies about the prognostic value of p53 in oesophageal cancer, and provide further insight into associations between risk factors and p53 alterations.

\section{Methods}

PATIENTS AND STUDY DESIGN

The study population comprised a sequentially accrued case series of 61 patients (50 men, 11 women) from southern Ontario, Canada, who underwent a curative resection of a primary oesophageal cancer between February 1991 and April 1995. All patients had a histologically documented diagnosis of primary oesophageal carcinoma from biopsies obtained at oesophagoscopy. Preoperative staging comprised radiological contrast studies (barium swallow) and computed tomography (CT) of the chest and upper abdomen. As was current clinical practice in Canada, no patient in this series received induction chemotherapy or radiotherapy. Total oesophagectomy was performed, completely resecting all macroscopic tumour. Regional lymph node stations were sampled extensively to document patterns of metastasis. Upper gastrointestinal continuity was re-established by interposing the stomach through the posterior mediastinum, with a cervical anastomosis. Postoperative surveillance comprised tri-monthly office visits, with yearly restaging, or as indicated clinically. All reasonable attempts were made to confirm tumour recurrence/metastasis cytologically or histologically, using radiologically guided fine needle aspiration or endoscopic biopsy techniques. Resected oesophageal tumours were evaluated for p53 alterations using polymerase chain reaction (PCR) based molecular assays to detect p53 mutations, and immunohistochemistry to detect $\mathrm{p} 53$ protein accumulation. An individual was considered to have altered p53 if they tested positive by either one of these assays. Patient risk factor data were collected preoperatively using a structured questionnaire to measure tobacco and alcohol consumption, intake of hot beverages, history of gastrooesophageal reflux disease and antacid use. Routine clinicopathological data were measured cross sectionally. Survival data were measured prospectively from date of resection to date of recurrence or metastasis (outcome, disease free survival), and date of last follow up or death (outcome, overall survival). Risk factor, clinicopathological, and survival data were collected blind to $\mathrm{p} 53$ status.

\section{TUMOUR ANALYSIS}

Use of resected oesophageal tissues was approved by review boards for health sciences research at the universities of Western Ontario (London) and Toronto, Ontario, Canada. In collaboration with a consultant gastrointestinal pathologist, resected oesophageal tumours were examined pathologically and staged according to the UICC TNM classification. The clinicopathological criteria used to define primary oesophageal adenocarcinoma were as follows ${ }^{6}$ : the presence of associated Barrett's epithelium (columnar epithelium lined oesophagus extending more than $3 \mathrm{~cm}$ above the oesophagogastric 
Table 2 Proportion of p53 alterations by selected clinicopathological findings

\begin{tabular}{|c|c|c|}
\hline & & p value \\
\hline$S e x$ & & $0.275(\mathrm{~F})$ \\
\hline Male & $74 \%(37 / 50)$ & \\
\hline Female & $55 \%(6 / 11)$ & \\
\hline Histology & & $1.000(\mathrm{~F})$ \\
\hline Squamous cell & $69 \%(9 / 13)$ & \\
\hline Adenomcarcinoma & $71 \%(37 / 48)$ & \\
\hline Site & & $1.000(\mathrm{~F})$ \\
\hline Upper (above carina) & $67 \%(2 / 3)$ & \\
\hline Lower (below carina) & $71 \%(41 / 58)$ & \\
\hline Differentiation & & 0.029 \\
\hline Well & $60 \%(6 / 10)$ & \\
\hline Moderate & $56 \%(14 / 25)$ & \\
\hline Poor & $88 \%(23 / 26)$ & \\
\hline Well/moderate & $57 \%(20 / 35)$ & $0.008^{\star}$ \\
\hline$T$ & & 0.328 \\
\hline 1 & $100 \%(3 / 3)$ & \\
\hline 2 & $55 \%(6 / 11)$ & \\
\hline 3 & $71 \%(32 / 45)$ & \\
\hline 4 & $100 \%(2 / 2)$ & \\
\hline$N$ & & 0.598 \\
\hline 0 & $67 \%(16 / 24)$ & \\
\hline 1 & $70 \%(7 / 10)$ & \\
\hline$M$ & & $1.000(\mathrm{~F})$ \\
\hline 0 & $71 \%(36 / 51)$ & \\
\hline 1 & $70 \%(7 / 10)$ & \\
\hline UICC stage & & 0.407 \\
\hline I & $100 \%(3 / 3)$ & \\
\hline IIA & $60 \%(12 / 20)$ & \\
\hline IIB & $50 \%(2 / 4)$ & \\
\hline III & $79 \%(19 / 24)$ & \\
\hline IV & $70 \%(7 / 10)$ & \\
\hline
\end{tabular}

$\mathrm{p}$ values are $\chi^{2}$ test, except those indicated by F, which are Fisher's exact test. $p$ values test the hypothesis of no differences in proportions.

$\star_{v}$ poor.

junction, or the presence of specialised "intestinal-type" epithelium); more than $75 \%$ of the tumour mass involving the tubular oesophagus; direct invasion of perioesophageal tissues histologically; minimal gastric involvement; and clinical symptoms of oesophageal obstruction (dysphagia). Tissues were placed in liquid nitrogen as soon as possible after resection, and were stored in the oesophageal tumour bank at $-80^{\circ} \mathrm{C}$ for molecular analysis. Tumour histology was confirmed by frozen section analysis at the time of processing, and by routine histology using haematoxylin and eosin. Samples were selected so that all tumour tissue comprised $>80 \%$ malignant cells, with minimal necrosis. For each tumour, matched histologically normal oesophageal mucosal tissue from the distant resection margin was used as an internal control.

MOLECULAR ANALYSIS OF THE p53 GENE

Genomic DNA was extracted from both normal and tumour tissues according to standard methods of proteinase $\mathrm{K} /$ sodium dodecyl sulphate (SDS) digestion, phenol/chloroform extraction, and ethanol precipitation. PCR/
SSCP analysis was used to detect p53 mutations in exons $4-10$ as described previously, ${ }^{6}$ with modifications in primer location and electrophoresis conditions. ${ }^{38}{ }^{39}$ Primers for exon 4 were: 5'-CCCCTGCACCAGCAGCTC CTA-3' (sense) and 5'-CAGGCATTGAAGT CTCATGG-3' (antisense); primers for exon 10 were: 5'-AACTCAGGTACTGTGAATAT ACT-3' (sense) and 5'-CAGGGGAGTA GGGCCAGTAA-3' (antisense). All samples were reamplified from the original genomic DNA, followed by a second PCR/SSCP analysis. Direct DNA sequencing (forward and reverse) was used to confirm the site and nature of the mutation.

IMMUNOHISTOCHEMISTRY

A modified indirect immunoperoxidase technique was used to study the distribution of p53 protein in formalin fixed, paraffin wax embedded $4 \mu \mathrm{m}$ thick tissue sections, as reported. ${ }^{36}$ Briefly, two primary anti-p53 antibodies (each recognising both mutant and wild-type p53) were used in separate assays: the murine monoclonal, DO7, and the rabbit polyclonal, CM1, at $1 / 25$ and $1 / 1000$ dilutions, respectively (Novacastra Laboratories, Newcastle upon Tyne, UK). Controls were run in parallel with test slides, and included known positive and negative staining tissues (tissue controls), test sections processed without the primary antibody (reagent controls), and matched histologically normal oesophageal mucosa (internal control). Tissue sections were evaluated independently by two investigators, one of whom was a consultant gastrointestinal pathologist. Discordant cases were discussed at the double headed microscope until consensus was reached. To overcome potential limitations of evaluating heterogenous tissues with variable immunoreactivity, and to minimise subjectivity, both the fraction of positive staining cell nuclei (proportion score: $0=$ none, $1=$ less than one hundredth, $2=$ one hundredth to one tenth, $3=$ one tenth to one third, $4=$ one third to two thirds, $5=$ greater than two thirds) and average staining intensity of positive cell nuclei (intensity score: $0=$ none, $1=$ weak, $2=$ moderate, $3=$ strong), were assigned to tissue sections. ${ }^{40}$ A composite score of $2-8$ was used to signify accumulation of $\mathrm{p} 53$ protein in tissue sections. All molecular and immunohistochemical assays were performed at least three times by the same laboratory technician, independently of the clinical correlative and outcome analysis.

Table 3 Statistics describing the association between p53 alterations and consumption of hot beverages

\begin{tabular}{|c|c|c|c|c|c|c|c|c|c|c|}
\hline \multirow[b]{2}{*}{ Variable } & \multirow[b]{2}{*}{ Mean } & \multirow[b]{2}{*}{ Median } & \multirow[b]{2}{*}{ Range } & \multirow{2}{*}{$\begin{array}{l}75-25 \text { th } \\
\text { percentile }\end{array}$} & \multicolumn{3}{|c|}{ Univariate analysis } & \multicolumn{3}{|c|}{ Multivariate analysis } \\
\hline & & & & & $\beta$ coefficient $^{*}$ & $p$ value & ORt & $\beta$ coefficient $\neq$ & $p$ value & ORt \\
\hline Usual beverage temperature (scale $1-10$ ) & 5.361 & 5 & $0-9$ & $8-3=5$ & 0.388 & 0.0006 & 6.993 & 0.518 & 0.0009 & 13.336 \\
\hline Daily average number of hot drinks & 3.296 & 2 & $0-10$ & $6-1=5$ & 0.492 & 0.0029 & 11.722 & 0.566 & 0.0038 & 16.920 \\
\hline Hot beverage index $₫$ & 23.836 & 12 & $0-90$ & $42-5=37$ & 0.0790 & 0.0025 & 18.597 & 0.0864 & 0.0025 & 24.454 \\
\hline
\end{tabular}

$\star \beta$ coefficient from logistic regression modelling with p53 alteration as a dependent variable, and one of the hot drink variables as a predictive variable. The $\beta$ coefficient taken to the natural $\log$ provides the estimated odds ratio (OR) for one unit of difference in the variable.

fOR 75 th -25 th $\%$ is the odds ratio comparing the 75 th to the 25 th percentile.

$\ddagger$ The multivariate model is adjusted for alcohol consumption and tumour differentiation.

$§$ Hot beverage index is usual beverage temperature times daily average number of hot drinks. 

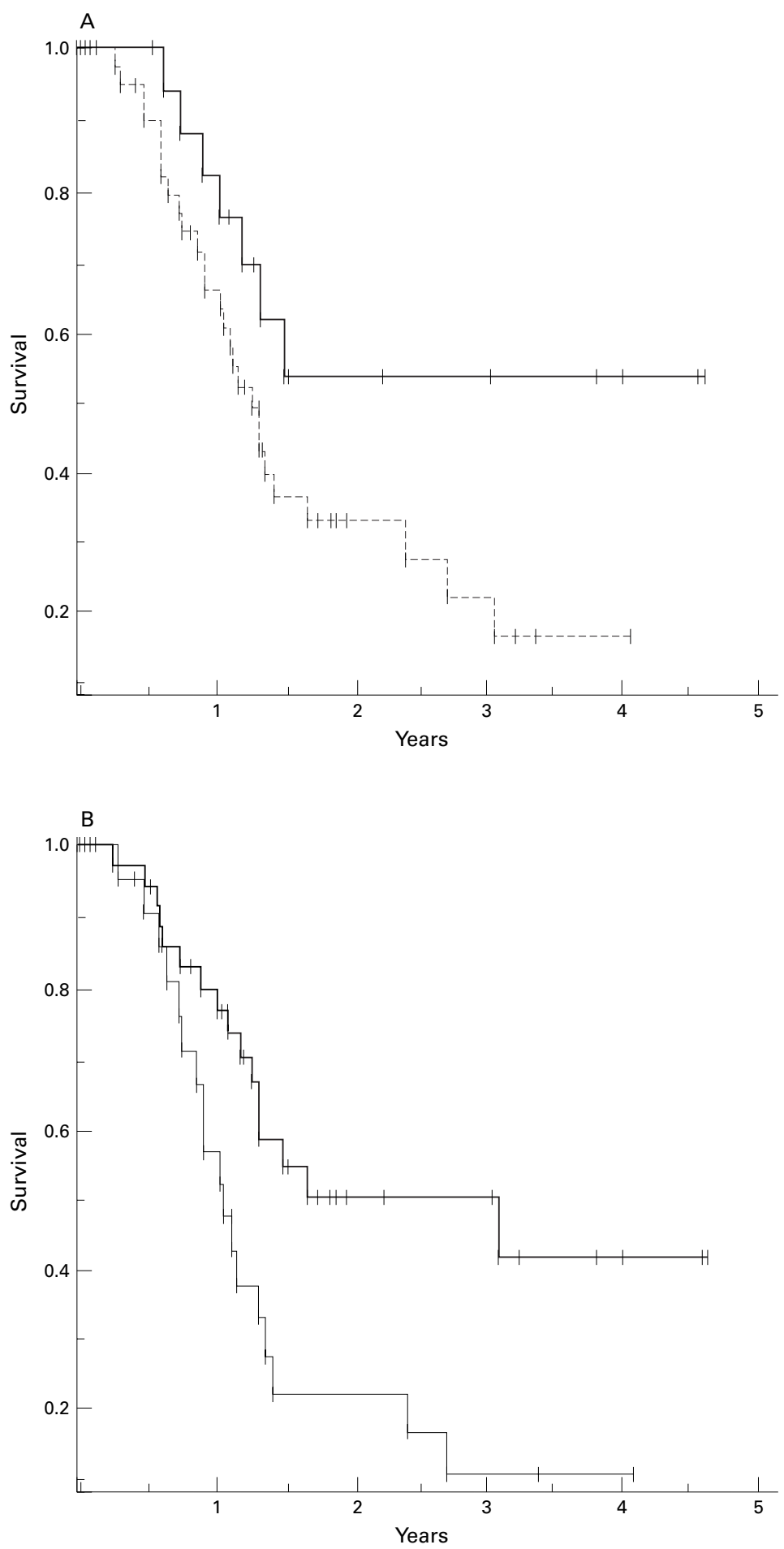

Figure 1 (A) Kaplan-Meier survival curves of overall survival for patients with oesophageal cancer categorised by $p 53$ status. The solid line indicates patients with wild-type p53, and the broken line indicates patients with $p 53$ alterations (mutations and/or protein accumulation) ( $p=0.51, \log$ rank). (B) Kaplan-Meier survival curves of overall survival for patients with oesophageal cancer categorised by p53 protein accumulation alone $(p=0.009, \log$ rank $)$. rank tests, and in multivariate analysis using Cox's proportional hazards model of relevant prognostic variables. Cox's proportional hazards model's included parsimonious, as well as fully adjusted models, and variables such as TNM or stage, that wereconsidered a priori to be relevant prognostic variables, were forced into all models. In parsimonious models, variable selection used the stepwise modelling strategy with values for entry set at $p=0.20$, and values for staying set at $p=0.10$. Cox's proportional hazards model assumptions of constant proportional hazards were evaluated and found to be satisfied. For hypothesis testing, statistical significance was set at $\alpha=0.05$. All $\mathrm{p}$ values reported are two sided. Statistical analysis was performed using SAS software (SAS 6.11; SAS, Cary, North Carolina, USA).

\section{Results}

CLINICOPATHOLOGICAL FINDINGS

The mean age of patients at the time of oesophageal resection was 64 years (range, 42-79 years). No patient was lost to follow up. The median duration of follow up for all patients was 14 months. Thirty four of the 61 patients in this series died from recurrent or metastatic oesophageal cancer. This was confirmed cytologically or histologically in $74 \%$ (25 of 34) of patients. In patients who did not undergo biopsy, the diagnosis of recurrent/ metastatic cancer was made radiographically with progression of a lesion on follow up studies, or the development of additional lesions. Follow up of surviving patients ranged from six to 55 months (median, 26 months). Tumour histology was squamous cell carcinoma (13 patients; $21 \%$ ) or adenocarcinoma (48 patients; $79 \%$ ). Differentiation of tumours was poor (26 tumours; 43\%), moderate (25 tumours; $41 \%$ ), or well differentiated (10 tumours; 16\%). Postresection tumour stage (UICC, pTNM) was I, three patients; IIA, 20 patients; IIB, four patients; III, 24 patients; and IV, 10 patients.

\section{p53 ALTERATIONS}

p53 mutations, confirmed by DNA sequencing, were found in $59 \%$ (36 of 61 ) of tumours, and localised to exons $4(\mathrm{n}=2), 5(\mathrm{n}=12), 6$ $(\mathrm{n}=3), 7(\mathrm{n}=5), 8(\mathrm{n}=8), 9(\mathrm{n}=3)$, and 10 $(\mathrm{n}=3)$. Missense mutations comprised single base substitutions $(n=17)$ and one in-frame deletion. Truncating mutations comprised nonsense mutations ( $n=9)$, base insertions $(\mathrm{n}=5)$, base deletions $(\mathrm{n}=3)$, and one splice site alteration (table 1). Overall, single base substitutions were G:C to A:T $(n=18), G: C$ to T:A $(n=4), A: T$ to T:A $(n=2), T: A$ to C:G $(n=2)$, and T:A to G:C $(n=1)$. For the subgroup of adenocarcinomas, single base substitutions $(n=22)$ were $G: C$ to $A: T$ $(n=17), T: A$ to $C: G(n=2), G: C$ to $T: A$ $(n=1)$, and $T: A$ to $G: C(n=1)$. Sixteen of these changes were at $\mathrm{CpG}$ dinucleotides. PCR/SSCP analysis of matched normal DNA demonstrated no electrophoretic mobility shifts (also confirmed by sequence analysis of 
Table 4 Selected prognostic variables (Cox's proportional hazards model) for overall and disease free survival for oesophageal cancer

\begin{tabular}{|c|c|c|c|c|c|c|}
\hline & \multicolumn{3}{|c|}{ Overall survival } & \multicolumn{3}{|c|}{ Disease free survival } \\
\hline & Hazard ratio & $95 \% C L$ & pvalue & Hazard ratio & $95 \% C L$ & $p$ value \\
\hline Age & 0.957 & $0.921,0.996$ & 0.0290 & 0.950 & $0.914,0.988$ & 0.0102 \\
\hline Site & 0.068 & $0.015,0.302$ & 0.0004 & 0.044 & $0.009,0.211$ & 0.0102 \\
\hline UICC stage & 1.482 & $1.023,2.147$ & 0.0375 & 1.574 & $0.084,2.285$ & 0.0172 \\
\hline p53 alterations & 3.124 & $1.213,8.046$ & 0.0183 & 3.366 & $1.283,8.828$ & 0.0136 \\
\hline
\end{tabular}

CL, confidence limits.

selected normals), indicating that p53 mutations in oesophageal tumours were somatic in origin.

p53 protein accumulation was found in 39\% (24 of 61 ) of tumours. Cell nuclear immunoreactivity was characteristic, and cytoplasmic staining was not seen. Immunoreactivity varied for individual positive cell nuclei, and p53 protein distribution was generally heterogenous throughout tumour tissues. However, concordance between independent investigators interpreting the slides was found in over $90 \%$ of cases. Consistent immunoreactivity was seen using either the monoclonal (DO7) or polyclonal (CM1) antibody. In all immunopositive tumours, the composite score was $\geq 4$. No immunoreactivity was seen in any negative control, or in matched histologically normal oesophageal mucosal tissue. There was $80 \%$ agreement between p 53 protein accumulation and missense mutations, and 52\% agreement between immunohistochemistry and truncating mutations. No mutations were found in six of 24 immunopositive tumours.

p53 ALTERATIONS AND CLINICOPATHOLOGICAL FINDINGS

Eighty eight per cent (23 of 26) of poorly differentiated oesophageal cancers had p53 alterations (gene mutations and/or protein accumulation) compared with $57 \%$ (20 of 35)

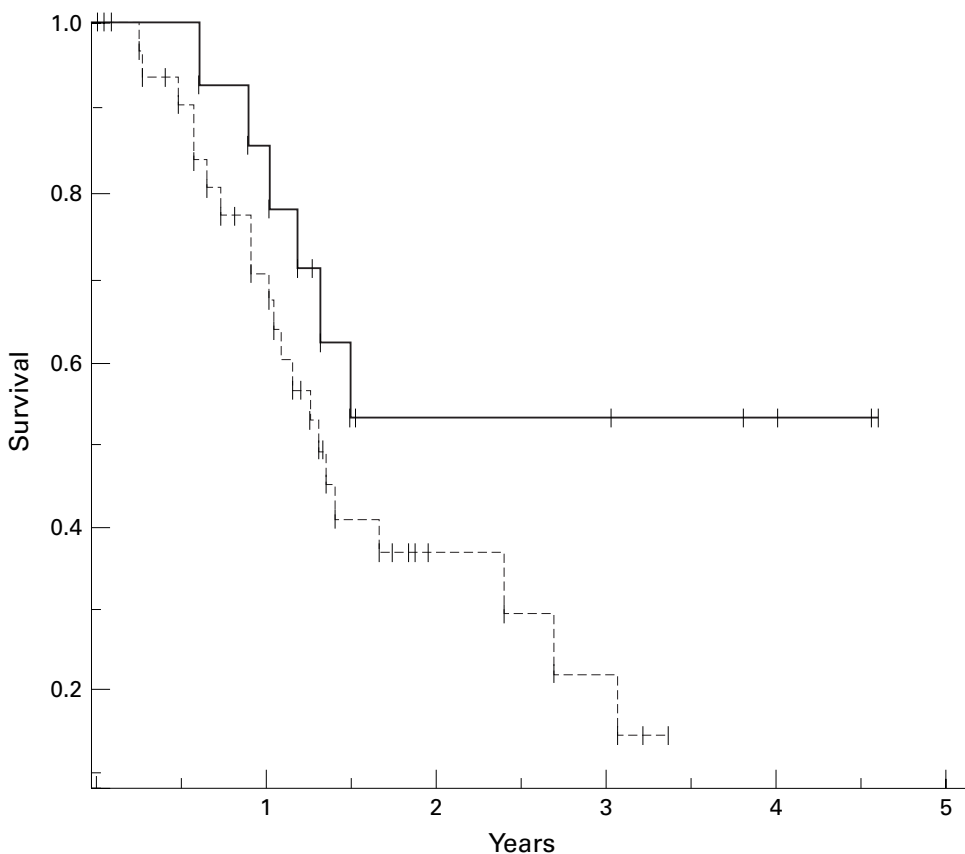

Figure 2 Kaplan-Meier survival curves for patients with primary oesophageal adenocarcinomas categorised by $p 53$ status (gene mutations and/or protein accumulation, broken line; wild-type p53, solid line) $(p=0.148$, log rank). of moderate/well differentiated tumours (odds ratio $(\mathrm{OR})=5.75 ; \mathrm{p}=0.013)$. Clinicopathological factors not associated with p53 alterations, in univariate or multivariate analysis, included age, sex, histological type, tumour site, $\mathrm{T}, \mathrm{N}, \mathrm{M}$, and overall stage (table 2).

p53 ALTERATIONS AND RISK FACTORS

p53 alterations increased significantly with increasing consumption of hot beverages (table 3). This relation was observed in both univariate and multivariate analysis, when measured by the average temperature of beverage consumed (on a 1-10 scale), the average daily number of hot beverages consumed, or an index made by multiplying the two variables together (hot beverage index). An inverse trend between increasing alcohol consumption and p53 alterations was found to achieve borderline significance $(\mathrm{OR}=0.53 ; \mathrm{p}=0.093)$. Risk factors not found to be associated with p53 alterations included history of gastro-oesophageal reflux disease, antacid use, and cigarette smoking.

p53 ALTERATIONS AND SURVIVAL

p53 alterations (mutations and/or protein accumulation) in oesophageal tumours were associated with reduced postoperative overall and disease free survival that approached statistical significance by the log rank test ( $p=0.051$ and $p=0.069$, respectively). Immunohistochemical analysis of p53 protein alone was also associated with significantly reduced postoperative overall and disease free survival ( $\mathrm{p}=0.009$ and $\mathrm{p}=0.01$, respectively), by $\log$ rank analysis. Kaplan-Meier survival curves for overall survival are presented in fig 1. The univariate (unadjusted) hazard ratio (HR) comparing tumours with p53 alterations to those with wild-type p53 was 2.241 $(95 \%$ confidence limits $(C L)=0.973,5.159$; $\mathrm{p}=0.058)$ for overall survival, and $2.129(95 \%$ $\mathrm{CL}=0.922,4.913 ; \mathrm{p}=0.076)$ for disease free survival.

Multivariate proportional hazards models were evaluated to obtain an estimate of the hazard ratio for p53 alterations adjusted for other potentially relevant prognostic variables. Parsimonious models from a stepwise procedure ( $\mathrm{p}$ values $<0.10$ (stage, site, and age)), as well as fully adjusted models including additional variables of potential prognostic importance (histology and tumour differentiation) were evaluated. In these models, oesophageal tumours with p53 alterations had increased hazard ratios, which is indicative of reduced overall and disease free survival (table 4). In the parsimonious model, the estimated 
hazard ratio for tumours with p53 alterations was $3.124 \quad(95 \% \quad \mathrm{CL}=1.213,8.046$; $\mathrm{p}=0.018)$ for overall survival, and $3.366(95 \%$ $\mathrm{CL}=1.283,8.828 ; \mathrm{p}=0.014)$ for disease free survival. In the fully adjusted model, the estimated hazard ratio for tumours with p53 alterations was $2.913 \quad(95 \% \quad \mathrm{CL}=1.069$, $7.936 ; \mathrm{p}=0.036)$ for overall survival and $3.145(95 \% \mathrm{CL}=1.158,8.546 ; \mathrm{p}=0.024)$ for disease free survival.

Comparable estimates of survival were seen when the analysis was restricted to adenocarcinomas only (fig 2), where the hazard ratio for tumours with p53 alterations was $3.364(95 \%$ $\mathrm{CL}=0.988,11.449 ; \mathrm{p}=0.052)$ for overall survival, and 2.845 (95\% CL $=0.899,9.002$; $\mathrm{p}=0.075$ ) for disease free survival. The hazard ratio comparing mutations in conserved regions (codons 17-29, 97-292, and 324-352) to non-conserved regions was estimated at 0.996 (95\% CL $=0.479,2.073 ; \mathrm{p}=0.992)$. Similarly, the classification of p53 mutations as missense and truncating was of no prognostic value in this series.

\section{Discussion}

Using molecular and immunohistochemical techniques to characterise the spectrum of p53 alterations in surgically resected oesophageal cancers, we found $59 \%$ of tumours in this series to have mutations, and $39 \%$ to have p53 protein accumulation. The finding of p53 alterations (gene mutations and/or protein accumulation) was associated with poor tumour differentiation, increased intake of hot beverages, and with significantly reduced postoperative survival.

Since the original reports of p53 mutations in primary oesophageal cancers, ${ }^{56}$ several studies have analysed patterns of p53 mutations in oesophageal tumours from various geographical regions. ${ }^{41}$ Because most larger series originate from high incidence areas, data on squamous cell carcinomas predominate. Of 240 oesophageal squamous cell cancers studied worldwide, $46 \%$ were found to have p53 mutations confirmed by sequencing, with a high percentage of mutations at codons 175 , $193,194,195$, and 270. In general, most studies have evaluated only exons $5-8$, representing the conserved region of p53, where the majority of mutations have been shown to occur. To date, no p53 mutations have been reported in exons 1-4 in oesophageal cancer, and only one p53 mutation was found in exon 11 (codon 342) in a Japanese squamous cell tumour. ${ }^{26}$ In this series, from a low incidence region, eight of 13 squamous cell carcinomas were found to have p53 mutations, located throughout exons 4, 5, 6, 8, 9, and 10. Although a high frequency of $\mathrm{G}: \mathrm{C}$ to $\mathrm{A}: \mathrm{T}$ transversions was reported for oesophageal squamous cell tumours from high incidence areas, suggesting involvement of exogenous carcinogens, this pattern of mutations was not seen in the small number of squamous cell cancers analysed in our series.

In contrast, the prevalent histological subtype of oesophageal carcinoma in our series of patients was adenocarcinoma. Although this may reflect the increasing incidence of oesophageal adenocarcinomas reported in North America, it may also simply indicate patterns of referral to tertiary or university thoracic surgical services. From combined series worldwide to date, sequence confirmed p53 mutations (exons 5-8) have been documented in $46(72 \%)$ of the 64 oesophageal adenocarcinomas studied. Unfortunately, most studies failed to define criteria for adenocarcinomas of primary oesophageal origin, raising the distinct possibility that adenocarcinomas of the stomach or gastric cardia were included in these series. To overcome this limitation, we adhered to strict clinicopathological guidelines ${ }^{6}$ developed at the outset of this study in an attempt to define adenocarcinomas of primary oesophageal (versus gastric) origin. In this study of 48 primary oesophageal adenocarcinomas, which is three quarters of the world experience to date with this histological subtype, we found 28 (48\%) p53 mutations through exons $4-10$. As reported in previous studies, we also found a high frequency $(77 \% ; 17$ of 22 base substitutions) of $\mathrm{G}: \mathrm{C}$ to $\mathrm{A}: \mathrm{T}$ transitions in oesophageal adenocarcinomas, 16 of which occurred at $\mathrm{CpG}$ dinucleotides. The odds ratio comparing CpG mutations versus all other mutations in this study was 22.44 (95\% CL: 1.18, 426.76). Such transitions at $\mathrm{CpG}$ dinucleotides suggest that p53 mutations may occur spontaneously by deamination or mismatch repair in primary oesophageal adenocarcinomas. This is in contrast to the spectrum of p53 mutations reported in oesophageal squamous cell carcinomas, where transitions at $\mathrm{CpG}$ dinucleotides are uncommon. ${ }^{41}$

We also evaluated $\mathrm{p} 53$ protein distribution in oesophageal tissues, which was found in $39 \%$ of tumours. The relative merits of using immunohistochemistry and mutational analysis to assess p53 status in breast cancer were reviewed in a recent editorial about this controversial issue, ${ }^{42}$ and the principles arising from this discussion are also relevant to other solid human tumours. To overcome the limitations of immunohistochemistry, all tissue sections were processed in the same manner by one technician, and all assays were repeated at least three times. Furthermore, we evaluated multiple tissue sections, utilised two anti-p53 antibodies in independent assays, and used a scoring system that incorporated the proportion and intensity of immunoreactivity. ${ }^{40}$ Consistent results were obtained by independent investigators evaluating the slides, who were blinded to the results of the molecular analysis. As expected, p53 protein accumulation was not detected immunohistochemically in all tumours with p53 mutations. Agreement between immunohistochemistry and the molecular finding of a missense or truncating mutation was $80 \%$ and $52 \%$, respectively. In the six tumours that were found to express p53 protein only, it is possible that mutations outside the exons screened remain undetected, or that wild-type $\mathrm{p} 53$ protein was stabilised by other cellular or viral proteins resulting in positive immunostaining. 
The study of associations between p53 alterations and clinicopathological characteristics, risk factors, and outcome was exploratory in nature. Because multiple comparisons were made, one would expect to find some significant associations, owing to random chance sampling alone, in about one in 20 comparisons (with the $\alpha$ error set at 0.05 ). To reduce the number of potential comparisons by $66 \%$, this study focused a priori on the results of $\mathrm{p} 53$ alterations based on the combination of both immunohistochemistry (protein) and PCR/ $\mathrm{SSCP} /$ sequencing (mutations). Approximately 40 serious comparisons were evaluated, with the following associations.

Poor differentiation of tumours was significantly associated with an increased chance of having a p53 alteration. This association is supported by results of other studies of related upper aerodigestive tract malignancies, including head and neck cancers ${ }^{43}$ and non-small lung cancers. ${ }^{44}$ The increasing consumption of hot beverages as a risk factor for $\mathrm{p} 53$ alterations was also found to be highly significant, and has not previously been reported. This finding was consistent across the different variables used to measure intake of hot beverages (table 3), and therefore seems unlikely to be the result of random chance (type I error). Furthermore, the strong dose response relation between hot beverage intake and p53 alterations in this study implicates beverage temperature as a risk factor for developing oesophageal cancer, and in particular p53 mediated oesophageal carcinoma. This observation is particularly interesting, as previous epidemiological studies reported an association between oesophageal cancer and intake of hot mate (herbal tea) in South America, ${ }^{45}{ }^{46}$ and hot calvados in France. ${ }^{47}$ However, the relatively limited numbers of patients in this study precluded further statistical analysis between patterns of p53 mutations and intake of hot beverages. Further confirmatory studies should also consider not only the temperature, but also the nature and chemical content of beverages.

Although cigarette smoking, history of gastro-oesophageal reflux disease, and prolonged antacid use have been implicated as environmental risk factors in the development of oesophageal cancer, we found no statistical associations between these risk factors and the presence or absence of $\mathrm{p} 53$ alterations. Of note, there was no association between smoking history and nucleotide transversions, compared to transitions. However, it should be remembered that these findings are based on a limited sample size, and further studies are warranted to define potential interactions between p53 and environmental risk factors. The relation between alcohol consumption and p53 mutations in oesophageal cancer remains unclear.

The p53 tumour suppressor gene has been proposed as a potentially clinically useful prognostic marker for a wide variety of human cancers. ${ }^{48}$ For oesophageal cancer, only one study has evaluated the prognostic value of p53 mutations, detected in exons $5-8$ by SSCP analysis only. ${ }^{37}$ Suspected mutations were not characterised by sequencing. To date, prognos- tic studies of oesophageal cancer have used immunohistochemistry to detect p53 protein accumulation as an indicator of genetic alteration. Although methodological variations including use of different anti-p53 antibodies, technique of tissue preparation, and interpretation of immunoreactivity may account for the discordant results reported, inconsistent use of preoperative induction therapies, different surgical techniques, and variable tumour staging also differ considerably between reported studies. Therefore, we have attempted to adhere to methodological guidelines proposed for clinical/laboratory interface studies on prognostic factors, ${ }^{49}$ evaluating a potentially clinically relevant molecular marker in a well defined patient population.

As with other solid human tumours, stage remains the most important conventional prognostic factor for oesophageal carcinoma. In this series, all tumours were staged pathologically according to the UICC TNM classification for carcinoma of the oesophagus, and advanced tumour stage was associated with reduced overall and disease free survival. This study also found that p53 alterations were associated with significantly reduced overall and disease free survival after surgical resection of oesophageal cancers. The magnitude of risk, which is in the order of threefold in most models evaluated, is clinically important, because survival with oesophageal cancer is generally poor. Estimates of hazard ratios for p53 alterations remain raised and significant in fully adjusted Cox models, indicating that for these data, the findings are not the result of confounding by stage, sex, age, tumour histology, or differentiation. However, it should be emphasised that these findings are based on a relatively limited sample size, and interpretation of results regarding the association between p53 alterations and prognosis need to be confirmed in larger prospective multicentre studies. Furthermore, recognising that oesophageal malignancy is relatively uncommon in North America, this study evaluated both oesophageal squamous cell carcinomas and adenocarcinomas to increase the sample size and enhance study power. Superficially, this appears justifiable, as strict criteria were used to define adenocarcinomas of oesophageal (not gastric cardia) origin, and by analysis, tumour histology alone did not approach significance as a predictor of p53 alterations or prognosis. This situation is somewhat analogous to non-small cell lung cancer, where squamous cell cancers, adenocarcinomas, and large cell tumours are grouped for research and analytical purposes. Furthermore, when the subgroup of oesophageal adenocarcinomas was studied alone, results were essentially no different from the pooled results.

The optimal method of assessing p53 status for prognostic studies in human carcinomas remains controversial. To date, immunohistochemical evaluation of $\mathrm{p} 53$ protein accumulation in oesophageal tumours has been used exclusively for prognostic studies. Indeed, immunohistochemical detection of p53 
protein in this series of oesophageal tumours was also associated with significantly reduced postoperative survival (fig $1 \mathrm{~B}$, table 4). Therefore, from the clinical standpoint of using p53 as a prognostic marker in oesophageal cancer, currently, the simplest and most practical approach is the use of immunohistochemistry alone to detect $\mathrm{p} 53$ protein accumulation. This strategy was also suggested for prognostic studies on p53 in breast cancer. ${ }^{49}$ Recognising the limitations of this technique, it is essential that individual laboratories should standardise and validate immunohistochemical methodology. However, as shown in this study, molecular analysis of p53 using $\mathrm{PCR} / \mathrm{SSCP}$ sequencing provides valuable biological data about the molecular genetic events underlying oesophageal cancer development, in addition to providing complementary prognostic information to immunohistochemistry alone.

In conclusion, this study has characterised the spectrum of p53 alterations (gene mutations and protein accumulation) in a well defined series of patients undergoing surgical resection of oesophageal carcinoma. p53 alterations were shown to be associated with poor tumour differentiation, increased intake of hot beverages, and poor survival. If these pilot observations are confirmed in larger prospective studies, p53 should be considered as a clinically relevant molecular marker in future clinical trials, and as a potentially useful biomarker for molecular epidemiological studies of oesophageal cancer, worldwide.

This work was supported in part by grants from the J P Bickel Foundation, the Canadian Association of General Surgeons, the Ontario Thoracic Society, and the Victoria Hospital Research Ontario Thoracic Society, and the Victoria Hospital Research
Development Fund. We thanks Drs Chambers, Troster, Inculet, Development Fund. We thanks Drs Chambers, Troster, Inculet, McCart, and O'Malley for help with these studies; Ms $\mathrm{N}$ Kerkvliet for technical assistance; and Ms $\mathrm{N}$ Zankowicz for
clinical data management. We also thank Drs R Montesano and clinical data management. We also thank Drs R Montesano and P Hainaut (International Agency for Research on Cancer, Lyon,
France) and Professor C Wild (University of Leeds, UK), for France) and Professor C Wild (U
critical review of this manuscript.

1 DeVesa SS, Blot WJ, Stone BJ, et al. Recent cancer trends in the United States. F Natl Cancer Inst 1995;87:175-82.

2 Farrow DC, Vaughan TL. Determinants of survival following the diagnosis of esophageal adenocarcinoma (United ing the diagnosis of esophageal adenocarcin

3 Greenblatt MS, Bennett W P, Hollstein M, et al. Mutations in the p53 tumor suppressor gene: clues to cancer etiology and molecular pathogenesis. Cancer Res 1994;54:4855-78.

4 Hollstein M, Shomer B, Greenblatt, et al. Somatic point mutations in the $\mathrm{p} 53$ gene of human tumors and cell lines: updated compilation. Nucleic Acids Res 1996;24:141-6.

5 Hollstein MC, Metcalf RA, Welsh JA, et al. Frequent mutation of the p53 gene in human esophageal cancer. Proc Nat Acad Sci USA 1990;87:9958-61.

6 Casson AG, Mukhopadhyay T, Cleary KR, et al. p53 gene mutations in Barrett's epithelium and esophageal cancer. Cancer Res 1991;51:4495-9.

7 Bennett WP, Hollstein MC, He A, et al. Archival analysis of p53 genetic and protein alterations in Chinese esophageal cancer. Oncogene 1991;6:1779-84.

8 Bennett WP, Hollstein MC, Metcalf RA, et al. p53 mutation and protein accumulation during multistage human esophageal carcinogenesis. Cancer Res 1992;52:6092-7.

9 Jankowshi J, Coghill G, Hopwood D, et al. Oncogenes and onco-suppressor gene in adenocarcinoma of the esophagus. Gut 1992;33:1033-8.

10 Gao H, Wang L-D, Zhou Q, et al. p53 tumor suppressor gene mutation in early esophageal precancerous lesions and carcinoma among high-risk populations in Henan, China. Cancer Res 1994;54:4342-6.

11 Neshat K, Sanchez CA, Galipeau PC, et al. p53 mutations in Barrett's adenocarcinoma and high-grade dysplasia. Gastroenterology 1994;106:1589-95.

12 Hamelin R, Flejou J-F, Muzeau F, et al. TP53 gene mutations and $\mathrm{p} 53$ protein immunoreactivity in malignant and premalignant Barrett's esophagus. Gastroenterology 1994;107:1012-18
13 Liang Y-Y, Esteve A, Maretl-Planche G, et al. p53 mutations in esophageal tumors from high-incidence areas of China. in esophageal tumors from high

14 Galiana C, Lozano J-C, Bancel B, et al. High frequency of Ki-ras amplification and p53 gene mutations in adenocarcinomas of the human esophagus. Mol Carcinog 1995;14: 286-93.

15 Gleeson CM, Sloan JM, McGuigan JA, et al. Base transitions at $\mathrm{CpG}$ dinucleotides in the $\mathrm{p} 53$ gene are common in esophageal adenocarcinoma. Cancer Res 1995;55. 3406-11.

16 Campomenosi $\mathrm{P}$, Conio $\mathrm{M}$, Bogliolo $\mathrm{M}$, et al. $\mathrm{p} 53$ is frequently mutated in Barrett's metaplasia of the intestinal type. Cancer Epidemiol Biomarkers Prevent 1996;5:559-65.

17 Huang Y, Meltzer SJ, Yin J, et al. Altered messenger RNA and unique mutational profiles of p53 and Rb in human esophageal carcinomas. Cancer Res 1993;53:188994.

18 Sorsdahl K, Casson AG, Troster M, et al. p53 and ras gene expression in human esophageal cancer and Barrett's epithelium: a prospective study. Cancer Detect Prevent 1994;18:179-85.

19 Sasano H, Miyazaki S, Goukon Y, et al. Expression of p53 in human esophageal carcinoma: an immunohistochemical study with correlation to proliferating cell nuclear antigen expression. Hum Pathol 1992;23:1238-43.

20 Younes M., LeBovitz RM, LeChago LV, et al. p53 protein accumulation in Barrett's metaplasia, dysplasia, and carcinoma: a follow-up study. Gastroenterology 1993;105: 1637-42.

21 Flejou J-F, Potet F, Le Pelletier F, et al. Overexpression of p53 protein in Barrett's syndrome with malignant transformation. 7 Clin Pathol 1993;46:330-3.

22 Wang L-D, Hong J-Y, Qiu S-L, et al. Accumulation of p53 protein in human esophageal precancerous lesions: a possi1783-7.

23 Volant A, Nousbaum J-B, Giroux M-A, et al. p53 protein accumulation in oesophageal squamous cell carcinom and precancerous lesions. $\mathscr{f}$ Clin Pathol 1995;48:531-4.

24 Moskaluk CA, Heitmiller R, Zahurak M, et al. p53 and $\mathrm{p} 21^{\mathrm{WAF} 1 / \mathrm{CIP} 1 / \mathrm{SD} 11}$ gene products in Barrett's esophagus and adenocarcinoma of the esophagus and esophagogastric junction. Hum Pathol 1996;27:1211-20.

25 Meltzer SJ, Yin J, Huang Y, et al. Reduction to homozygosity involving p 53 in esophageal cancers demonstrated by
the polymerase chain reaction. Proc Natl Acad Sci USA the polymerase chair

26 Wagata T, Shibagaki I, Imamura M, et al. Loss of $17 \mathrm{p}$, mutation of the p53 gene, and overexpression of p53 protein in esophageal squamous cell carcinomas. Cancer Res 1993;53:846-50.

27 Blount PL, Galipeau PC, Sanchez CA, et al. 17p allelic losses in diploid cells of patients with Barrett's esophagus who develop aneuploidy. Cancer Res 1994;54;2292-5.

28 Furihata M, Ohtzuki Y, Ogoshi S, et al. Prognostic significance of human papillomavirus genomes (type-16,
-18) and aberrant expression of p53 protein in human esophageal cancer. Int f Cancer 1993;54:226-30.

29 Shiyama K, Shiozaki H, Inoue M, et al. Significance of p53 expression as a prognostic factor in oesophageal squamous cell carcinoma. Virchows Archiv A Pathol Anat 1993;422: 271-6.

30 Sarbia M, Porschen R, Borschard F, et al. p53 protein expression and prognosis in squamous cell carcinoma of the esophagus. Cancer 1994;74:2218-23.

31 Vijeyasingham R, Darnton SJ, Jenner K, et al. Expression of p53 protein in oesophageal carcinoma: clinicopathological correlation

32 Goukon Y, Sasano H, Nishihira T, et al. p53 overexpression in human esophageal carcinoma: a correlation with tumor DNA ploidy and two parameter flow cytometric study. Anticancer Res 1994;14:1305-12.

33 Wang D-Y, Xiang Y-Y, Tanaka M, et al. High prevalence of p53 protein overexpression in patients with esophageal cancer in Linxian, China and its relationship to progression and prognosis. Cancer 1994;74:3089-96.

34 Chanvitan A, Nekarda H, Casson AG. Prognostic value of DNA index, S-phase fraction, and p53 protein accumulation after surgical resection of esophageal squamous cell carcinomas in Thailand. Int f Cancer 1995;63:381-6.

35 Sauter ER, Keller SM, Erner SM. p53 correlates with improved survival in patients with esophageal adenocarcinoma. F Surg Oncol 1995;58:269-73.

36 Casson AG, Kerkvliet N, O'Malley F. Prognostic value of p53 protein in esophageal adenocarcinoma. F Surg Oncol 1995;60:5-11.

37 Coggi G, Bosari S, RoncalliM, et al. p53 protein accumulation and p53 gene mutation in esophageal carcinoma. Cancer 1997;79:425-32.

38 Ozcelik H, Andrulis IL. Multiplex PCR-SSCP for simultaneous screening for mutations in several exons of p53. Biotechniques 1995;18:742-3.

39 Ozcelik H, Mousses S, Andrulis IL. Low levels of expression of an inhibitor of cyclin-dependent kinases (CIP1/WAF1) in primary breast carcinomas with p53 mutations. Clin Cancer Res 1995;1:907-12.

40 Allred DC, Clark GM, Elledge R, et al. Association of p53 protein expression with cell proliferation rate and clinical outcome in node-negative breast cancer. $\mathcal{F}$ Natl Cancer Inst 1993;85:200-6. 
41 Montesano R, Hollstein M, Hainaut P. Genetic alterations in esophageal cancer and their relevance to etiology and pathogen $225-35$.

42 Elledge RM. Assessing p53 status in breast cancer prognosis: where should you put the thermometer if
you think your p53 is sick? Natl Cancer Inst 1996;88:141-3.

43 Shin DM, Lee JS, Lippman SM, et al. p53 expression: predicting recurrence and second primary tumors in head and neck squamous cell carcinoma. F Natl Cancer Inst 1996;88: 519-29.

44 Dalquen P, Sauter G, Torhorst J, et al. Nuclear p53 overexpression is an independent prognostic parameter in 1996;178:53-8.
45 Munoz N, Victora CG, Crespi M, et al. Hot mate drinking and precancerous lesions of the oesophagus: an endoscopic

46 Rolon PA, Castellsague X, Benz M, et al. Hot and cold mate drinking and esophageal cancer in Paraguay. Cancer Epidemiol Biomarkers Prevent 1995;4:595-605.

47 Launoy G, Milan C, Day NE, et al. Esophageal cancer in France: potential importance of hot alcoholic drinks. Int $\mathcal{F}$ Cancer 1997;71:917-23.

48 Harris CC, Hollstein M. Clinical implications of the p53 tumor suppressor gene. N Engl f Med 1993;329:1318-27.

49 McGuire WH. Breast cancer prognostic factors: evaluation guidelines. F Natl Cancer Inst 1991;83:154-5.

50 Hermanek P, Sobin LH, eds. TNM classification of malignant tumors. Berlin: Springer-Verlag, 1992. 